\title{
ASO Visual Abstract: Adjuvant Chemotherapy After Neoadjuvant Chemotherapy for Pancreatic Cancer is Associated with Improved Survival in Those with Low-Risk Pathology
}

\author{
Elizabeth J. Olecki, MD ${ }^{1}$, Kelly A. Stahl, MD ${ }^{1}$, Madeline B. Torres, MD ${ }^{1}$, June S. Peng, MD $^{2}$, \\ Matthew Dixon, $\mathrm{MD}^{2}$, Chan Shen, PhD $^{1,3}$, and Niraj J. Gusani, MD, MS, FACS ${ }^{3}$ \\ ${ }^{1}$ Department of Surgery, The Pennsylvania State University, College of Medicine, Hershey, PA; ${ }^{2}$ Program for Liver, \\ Pancreas, \& Foregut Tumors, Department of Surgery, The Pennsylvania State University, College of Medicine, Hershey, \\ PA; ${ }^{3}$ Section of Surgical Oncology, Baptist MD Anderson Cancer Center, Jacksonville, FL
}

With limited evidence, the benefit of adjuvant chemotherapy (AT) after completion of neoadjuvant chemotherapy (NT) and surgical resection in patients with pancreatic adenocarcinoma is debated. The National Cancer Database from 2006 to 2015 was used to identify patients undergoing NT. Results of this study (http://doi. org/10.1245/s10434-020-09546-8) suggest that, in patients with pancreatic adenocarcinoma, additional adjuvant chemotherapy is beneficial in subgroups with low-risk pathologic features who have undergone neoadjuvant chemotherapy and surgical resection.

\section{Adjuvant Chemotherapy After Neoadjuvant Chemotherapy for Pancreatic Cancer}

is Associated with Improved Survival in Those with Low Risk Pathology

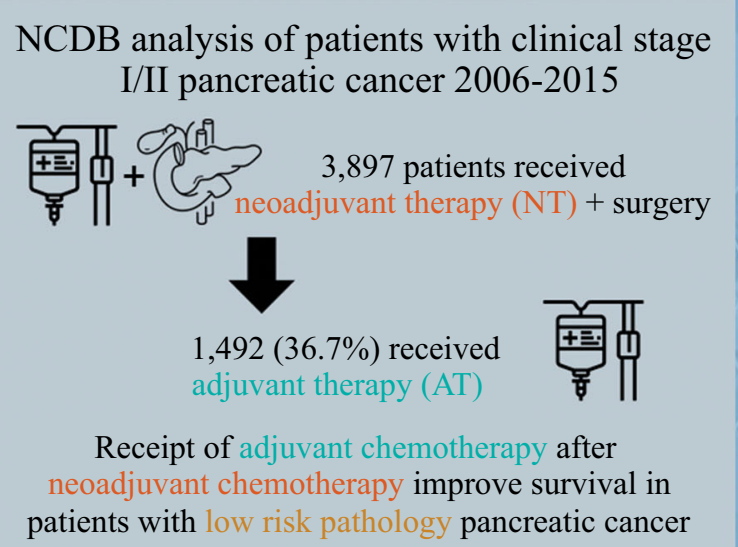

Olecki, et al. Ann Surg Oncol.

VisualAbstract by@elizabetholecki and@NirajGusani for@AnnSurgOncol

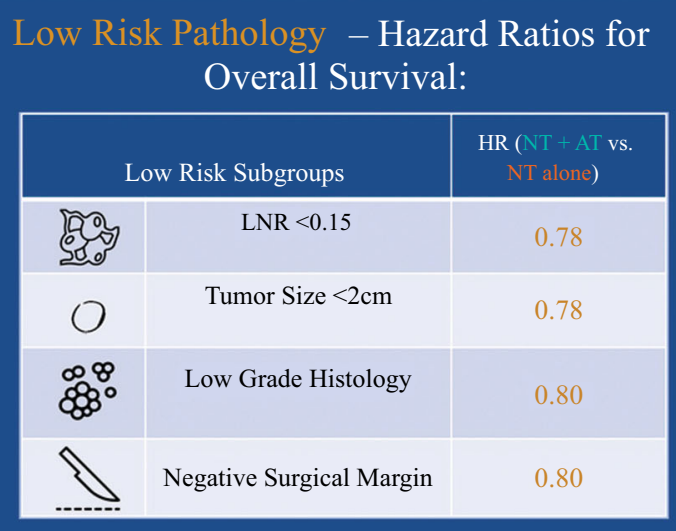

ANNALS OF

SURGICAL

ONCOLOGY

(C) Society of Surgical Oncology 2021

Publisher's NoteSpringer Nature remains neutral with regard to jurisdictional claims in published maps and institutional affiliations.

N. J. Gusani, MD, MS, FACS

e-mail: Niraj.Gusani@bmcjax.com 